\title{
A multiple antibiotic and serum resistant oligotrophic strain, Klebsiella pneumoniae MB45 having novel dfrA30, is sensitive to ZnO QDs
}

\author{
Arvind Kumar ${ }^{1}$, Soumynanda Chakraborti ${ }^{2}$, Prachi Joshi ${ }^{3}$, Pinak Chakrabarti ${ }^{2}$ and Ranadhir Chakraborty ${ }^{1 *}$
}

\begin{abstract}
Background: The aim of this study was to describe a novel trimethoprim resistance gene cassette, designated dfrA30, within a class 1 integron in a facultatively oligotrophic, multiple antibiotic and human serum resistant test strain, MB45, in a population of oligotrophic bacteria isolated from the river Mahananda; and to test the efficiency of surface bound acetate on zinc oxide quantum dots ( $\mathrm{n} \mathrm{nO}$ QDs) as bactericidal agent on MB45.

Methods: Diluted Luria broth/Agar $\left(10^{-3}\right)$ media was used to cultivate the oligotrophic bacteria from water sample. Multiple antibiotic resistant bacteria were selected by employing replica plate method. A rapid assay was performed to determine the sensitivity/resistance of the test strain to human serum. Variable region of class 1 integron was cloned, sequenced and the expression of gene coding for antibiotic resistance was done in Escherichia coli JM 109. Identity of culture was determined by biochemical phenotyping and 16S rRNA gene sequence analyses. A phylogenetic tree was constructed based on representative trimethoprim resistancemediating DfrA proteins retrieved from GenBank. Growth kinetic studies for the strain MB45 were performed in presence of varied concentrations of $\mathrm{ZnO}$ QDs.

Results and conclusions: The facultatively oligotrophic strain, MB45, resistant to human serum and ten antibiotics trimethoprim, cotrimoxazole, ampicillin, gentamycin, netilmicin, tobramycin, chloramphenicol, cefotaxime, kanamycin and streptomycin, has been identified as a new strain of Klebsiella pneumoniae. A novel dfr gene, designated as $\mathrm{dfr} A 30$, found integrated in class 1 integron was responsible for resistance to trimethoprim in Klebsiella pneumoniae strain MB45. The growth of wild strain MB45 was 100\% arrested at $500 \mathrm{mg} / \mathrm{L}$ concentration of $\mathrm{ZnO}$ QDs. To our knowledge this is the first report on application of $\mathrm{ZnO}$ quantum dots to kill multiple antibiotics and serum resistant K. pneumoniae strain.
\end{abstract}

\section{Background}

Klebsiellae are ubiquitously present in nature and have been isolated from wide variety of habitats like-human body parts, animals, sewage, soils, vegetation, lakes, salt water, brackish water, fresh water and sachet water [1-3]. Generally, they are opportunistic pathogen for humans and other animals [1]. At present, nine validly published species have been reported for Klebsiella $[4,5]$. The genus comprises of non-motile, gram-negative, rod-shaped bacteria having a prominent polysaccharide capsule which encloses the total cell surface and

\footnotetext{
* Correspondence: rcnbu2003@yahoo.com

'Omics Laboratory, Department of Biotechnology, University of North Bengal, Raja Rammohunpur, P.O. NBU, Siliguri 734 013, West Bengal, India Full list of author information is available at the end of the article
}

renders resistance against several host defense mechanisms [6-8]. Strains of K. pneumoniae conferring resistance to an extended spectrum $\beta$-lactams, carbapenems, cephalosporins, aminoglycosides, flouroquinolones together with the trimethoprim (TMP) and cotrimoxazole and other antibiotics, have been isolated from different clinical setup [9-13]. Trimethoprim is used as primary drug in the prophylaxis and treatment of both urinary and respiratory tract infections [14]. Resistance to trimethoprim is caused by modifications in the target enzyme dihydrofolate reductase, encoded by $d f r$ genes located either on plasmid or chromosome [15-20]. Different $d f r A$ genes ( $>25$ ) conferring resistance to trimethoprim have been reported and 15 of them were integron-borne [15,21-23]. Integrons are genetic
C Biomed Central 
elements that contain determinants of a site-specific recombination system by which they can excise or integrate gene cassettes (mobile element), usually antibiotic resistance genes encoding antimicrobial resistance $[24,25]$. Presence of class 1 integrons is documented in both eutrophic and oligotrophic bacteria isolated from Indian rivers of northern West Bengal [23,26]. There were number of attempts to cultivate oligotrophic bacteria using different diluted media $[27,28]$ including R2A media [29]. Recently, diluted Luria broth (LB) was used to cultivate oligotrophic bacteria from environmental sample [23,30]. There are reports on oligotrophic bacteria isolated from clinical materials [28] and quite a good number of oligotrophic bacteria in river waters exhibit antibiotic resistance [23,30]. Hence, oligotrophs could be a potential reservoir of antibiotic resistance genes that can be acquired by pathogens through diverse gene transfer mechanisms. Due to their potential clinical importance, oligotrophic bacteria merit attention. The prevalence of multiple antibiotic resistant bacteria among pathogens and by-standers (normally not pathogenic but becomes virulent under immunosuppressive conditions) poses a severe threat to public health worldwide. It is difficult to eradicate antibiotic resistant pathogenic bacteria which can survive in low nutrient condition for a long period of time (oligotrophs). As mortality and morbidity rate due to infection by multiple-antibiotic-resistant bacteria is on rise, novel therapeutic strategies are being devised to combat this problem. Metal oxide nanoparticles have shown antimicrobial property (31). Among different metal oxide nanoparticles, $\mathrm{ZnO}$ being non-toxic is popular due to its biocompatibility. Testing of $\mathrm{ZnO}$ Quantum dots as antimicrobials is mainly done on gram-negative antibioticsensitive strain of E. coli [31,32].

In this study, we have demonstrated the efficacy of $\mathrm{ZnO}$ Quantum dots to inhibit growth of an oligotrophic, multiple antibiotic and serum resistant strain of $K$. pneumoniae MB45 isolated from river Mahananda of Siliguri, West Bengal, India. We have also characterized and expressed a novel class 1 integron borne trimethoprim resistant $d$ fr $A$ gene, designated $d f r A 30$ from the said strain.

\section{Methods}

\section{Sampling, Isolation and selection of the Test strain, and} preparation of Antibiogram

The strain was isolated from river water sample. Sampling, isolation and identification of oligotrophic bacteria were done according to the methods described earlier [23]. Replica plating method was employed for determining the antibiogram of the isolate designated as MB45 [23]. Strain, MB45, resisting high level of trimethoprim (>1500 mg/L) was selected for this study. The susceptibility of MB45 tested as described previously [23]. Criteria for susceptibility followed the EUCAST guidelines http://www.eucast.org/clinical_breakpoints/. Susceptibility to the antibiotics absent in EUCAST breakpoints table (v 1.1 2010-04-27), were interpreted according to previously described criteria [23]. Strain was maintained by bi-weekly transfer to $\mathrm{R} 2 \mathrm{~A}$ agar slants (HiMedia, India) and stored at $-20^{\circ} \mathrm{C}$ in R2A broth amended with glycerol $(20 \% \mathrm{v} / \mathrm{v})$.

\section{Phenotypic and Phylogenetic characterization of MB45}

All phenotypic and biochemical test were performed following methodology described earlier [23] at $37^{\circ} \mathrm{C}$. Growths at different temperatures were tested in LB at $7,10,15,25,30,37$, and $45 \pm 1^{\circ} \mathrm{C}$. DNA for amplification of $16 \mathrm{~S}$ rRNA gene was extracted from cells (grown in $\mathrm{LB}$ for $4 \mathrm{hr}$ at $37^{\circ} \mathrm{C}$ ) by boiling lysis method. A loop full bacterial culture (24 h old) was inoculated in 100 $\mathrm{mL}$ flask containing $10 \mathrm{~mL} \mathrm{LB}$ and incubated for $4 \mathrm{hr}$ at $37^{\circ} \mathrm{C}$ without agitation. The cells $(0.5 \mathrm{~mL})$ were harvested by centrifuging at $6000 \mathrm{rpm}$ for 10 minute at $4^{\circ}$ C. The pellet was suspended in $200 \mu \mathrm{L}$ sterile distilled water and put in a microwave oven for $1.5 \mathrm{~min}$ at 800 watt (LG model No MS-194W). Lysate was cooled at room temperature and centrifuged at $8000 \mathrm{rpm}$ for 2 min to remove cell debris. $2 \mu \mathrm{L}$ of the resulting supernatant was used as template DNA in $25 \mu \mathrm{L}$ of PCR mix. Amplification, cloning and sequencing were done according to the previously described method [23].

Viability and Growth of MB45 in diluted $\left(10^{-3}\right)$ Luria-broth Inoculum was prepared by transferring a single colony of $24 \mathrm{~h}$ old culture of MB45 into $10 \mathrm{~mL}$ sterile LB (pH 7.0) in $100 \mathrm{~mL}$ Erlenmeyer flask. The inoculated medium was incubated at $37^{\circ} \mathrm{C}$ for $4 \mathrm{~h}$ without agitation. The culture was harvested by centrifuging at $8000 \mathrm{rpm}$ for $5 \mathrm{~min}$ at $4^{\circ} \mathrm{C}$ and washed twice with sterile saline $(0.5 \% \mathrm{NaCl})$ water to remove traces of media. The washed pellet was finally suspended in $3 \mathrm{~mL}$ sterile saline water. Aliquots of $1.0 \mathrm{~mL}$ of concentrated $\left(1 \times 10^{8}\right.$ cells $/ \mathrm{mL}$ ) cell suspension (s) were added to $25 \mathrm{~mL}$ of diluted $\left(10^{-3}\right) \mathrm{LB}$ in $250 \mathrm{~mL}$ Erlenmeyer flask. The flask was kept at $37^{\circ} \mathrm{C}$ (without shaking) throughout the period of investigation. Survivability of MB45 cells in $10^{-3}$ LB was assessed through dilution-plating of pure culture aliquots at different time intervals on fresh LA plates.

\section{Serum bactericidal assay}

Serum bactericidal assay was basically performed by the methods described by Sharma et al. [33].

\section{Growth kinetics of MB45 in presence of varied concentrations of $\mathrm{ZnO}$ QDs}

$\mathrm{ZnO}$ QDs with surface adsorbed acetate ions (particle size 3-5 $\mathrm{nm}$ ) was synthesized and characterized by 
methods described earlier [31]. Inoculum, for testing $\mathrm{ZnO}$ QDs efficacy, was prepared as described above. Aliquots of $10 \mu \mathrm{L}$ of concentrated $\left(9 \times 10^{7}\right.$ cells $)$ cell suspension(s) were added to $3.0 \mathrm{~mL}$ volume(s) of LB in 10 $\mathrm{mL}$ glass test tube(s) amended with different concentrations of $\mathrm{ZnO}$ QDs. The tube containing all the ingredients except ZnO QDs was taken as positive control. LB containing $\mathrm{ZnO}$ QDs but lacking cells were taken as negative control. The tubes were kept at $37^{\circ} \mathrm{C}$ with continuous agitation at $200 \mathrm{rpm}$ throughout the period of investigation. Each test was performed in triplicate. The optical density was measured in spectrophotometer (Model-302, Electronic India) at $600 \mathrm{~nm}$ at different time intervals. Growth rate constant $(\mu)$ and mean generation time ( $\mathrm{g}$ ) of MB45 in absence and presence of different concentrations of $\mathrm{ZnO}$ QDs were calculated.

\section{Phylogenetic affiliation of MB45}

Phylogenetic analysis of the $16 \mathrm{~S}$ rRNA gene sequences of MB45 and all the known species of genus Klebsiella were conducted in the software package MEGA4 [34]. Multiple alignments of sequences were done with CLUSTAL W [35]. Distances were calculated according to the Jukes-Cantor. Phylogenetic analyses were performed using two tree-making algorithms: the NJ (neighbor-joining) [36] and MP (maximum parsimony) [37] methods to ensure consistency of the clusters formed (data not shown). Tree topology was evaluated by the bootstrap re-sampling method of Felsenstein [38] based on 1000 replication.

\section{Detection of class 1 integron, cloning, sequencing, and expression of variable region}

Whole cell DNA was extracted as described above. Variable region of the class 1 integron was amplified using two sets of primer pair, 5" CS and 3" CS; and $\operatorname{Int}_{2} \mathrm{~F}$ and 3" CS described previously [39,40]. Cloning and sequencing were done according to the method described previously [23]. For determination of resistance coded by $d f r A 30$ gene, the amplicon was cloned in pGEM-T easy vector system-II (Promega, Madison, USA) and then transformed into $E$. coli JM109. Clones containing insert (CS-PCR product) in proper orientation were selected on LA plates containing IPTG and X-gal (for BlueWhite screening) and trimethoprim $(5 \mathrm{mg} / \mathrm{L})$. One of the clones (pAK45) appeared on trimethoprim amended LA plate was purified, stored and used for testing the maximum tolerance of trimethoprim. Plasmidless E. coli JM109 was used as control.

\section{Sequence analysis and phylogenetic position of the dfrA30 gene}

Each DfrA protein sequences were obtained from GenBank database (NCBI, http://www.ncbi.nlm.nih.gov/).
The phylogenetic analysis at the amino acid level of the DfrA30 (translated $d f r A 30$ gene) was done by constructing a phylogenetic tree based on one representative for each trimethoprim-resistance-mediating DfrA proteins. The multiple alignments were made using the program CLUSTAL W [35]. The phylogenetic tree was constructed using NJ tree-making algorithm. The consistency of the clusters formed was also validated by methods MP [37] and UPGMA (Unweighted Pair Group Method with Arithmetic mean) [41] (data not shown). Sequence alignment and phylogenetic analysis of the Dfr protein sequences were accomplished in MEGA4 [34].

Sequence alignment and the effect of mutation in DfrA30 To identify the residues responsible for trimethoprimresistance in the DfrA30, multiple sequence alignment of DfrA proteins [DfrA30, Ac. No. AM997279; DfrA5, Ac. No. AJ419169; and wild type (WT, trimethoprimsensitive) Dfr, Ac. No. J01609 ] was carried out using CLUSTAL W [35]. Due to the non availability of the trimethoprim-bound structure from E. coli in the Protein Data Bank (PDB) [42], sequence alignment was also performed between different trimethoprim-bound Dfr available in PDB. The protein from the Mycobacterium avium (PDB ID: 2W3V) gave the highest score and was used for the analysis of ligand binding. Pymol http:// www.pymol.org was used for molecular visualization.

\section{Nucleotide accession number}

The EMBL accession numbers for the 16S rRNA gene and $d f r A 30$ gene are respectively FR677021 and AM997279.

\section{Results}

Phenotypic and phylogenetic characterization of MB45

Cells of the strain MB45 were rod shaped, capsulated, gram negative, aerobic (facultative anaerobic) and nonmotile. On Luria agar, colonies were circular, convex, translucent, mucoid, sticky and off-white in colour with diameters of 2.0-3.0 mm after 3 days at $37^{\circ} \mathrm{C}$. Differential phenotypic and biochemical characteristics of the strain MB45 and nearest strains are given in Table 1. Antimicrobial susceptibility testing (recommended by EUCAST for Enterobacteriaceae) showed that the strain MB45 was resistant to trimethoprim $(\mathrm{S} \leq / \mathrm{R}>, 2 / 4 \mathrm{mg} /$ $\mathrm{L})$, cotrimoxazole $(\mathrm{S} \leq / \mathrm{R}>2 / 4 \mathrm{mg} / \mathrm{L})$, ampicillin $(\mathrm{R}>8$ $\mathrm{mg} / \mathrm{L})$, gentamycin $(\mathrm{S} \leq / \mathrm{R}>2 / 4 \mathrm{mg} / \mathrm{L})$, netilmicin $(\mathrm{S} \leq / \mathrm{R}$ $>2 / 4 \mathrm{mg} / \mathrm{L})$, tobramycin $(\mathrm{S} \leq / \mathrm{R}>2 / 4 \mathrm{mg} / \mathrm{L})$, chloramphenicol $(\mathrm{S} \leq / \mathrm{R}>8 / 8 \mathrm{mg} / \mathrm{L})$ and cefotaxime $(\mathrm{S} \leq / \mathrm{R}>1 / 4$ $\mathrm{mg} / \mathrm{L}$ ) and antibiotics, absent in EUCAST - kanamycin $(\mathrm{R} \geq 5 \mathrm{mg} / \mathrm{L})$ and streptomycin $(\mathrm{R} \geq 2.5 \mathrm{mg} / \mathrm{L})$. Nearly complete $16 \mathrm{~S}$ rRNA gene sequence $(1503 \mathrm{bp})$ was amplified, cloned and sequenced. The $16 \mathrm{~S}$ rRNA gene sequence similarities with phylogenetic neighbours were 
Table 1 Differential biochemical properties of $K$. pneumoniae MB45 from other Klebsiella species

\begin{tabular}{lcccc}
\hline Characteristics & MB45 & $\mathbf{1}$ & $\mathbf{2}$ & $\mathbf{3}$ \\
\hline Gas from Lactose at $44 \pm 1{ }^{\circ} \mathrm{C}$ & - & + & + & + \\
Methyl red & - & - & + & + \\
Voges Proskauer & + & + & - & - \\
Urease & - & + & - & - \\
ONPG\# & + & + & - & + \\
Malonate utilization & + & + & + & - \\
Lysine decarboxylate & + & + & - & $d$ \\
Ornithine decarboxylase & + & - & - & -
\end{tabular}

Strains: MB45; 1, K. pneumoniae subsp. pneumoniae; $2, K$. pneumoniae subsp. rhinoscleromatis; 3 , K. pneumoniae subsp. ozaenae

Abbreviations: +, positive; -, negative; $d, 11-89 \%$ positive; \#, o-nitrophenyl- $\beta$-Dgalactopyranoside

Data from this study and previous studies $[4,69,70]$

in the range $97.5-99.6 \%$. The closest species to the strain MB45 was K. pneumoniae subsp. rhinoscleromatis ATCC $13884^{\mathrm{T}}(99.6 \%$ sequence similarity). In the NJ tree constructed with 16S rRNA gene sequence of $K$. pneumoniae MB45 formed a tight clade with a bootstrap support of $83 \%$ with the cluster comprising the four Klebsiella strains named as $K$. pneumoniae subsp. pneumoniae, K. granulomatis, $K$. singaporensis and K. alba (Figure 1). Similar output was obtained from MP clustering (data not shown).

Growth of the strain MB45 in diluted $\left(10^{-3}\right)$ Luria broth The growth of MB45 cells were observed in diluted (10${ }^{3}$ ) LB lacking any extra supplementation of growth factor (Figure 2). An increase of 4.6 times of the initial cell number was noted in 2 days. The ability of MB45 to survive (without reduction in viable cell number since inoculation) and grow in a low nutrient medium explains the oligotrophic nature of the strain.

\section{Serum bactericidal activity}

The serum reactivity against the strain MB45 was determined by the rapid assay. MB45 could change the colour in NHS and HIS tubes at $5 \mathrm{~h}$ and therefore inferred as serum-resistant. The control isolate, E. coli $\mathrm{K} 12$ could not change the colour of NHS tube even at $8 \mathrm{~h}$, but turned HIS tube yellow at $5 \mathrm{~h}$, was regarded as serumsensitive.

\section{Effect of $\mathrm{ZnO}$ QDs on the growth of MB45}

The growth curves of MB45 in presence of different concentrations of $\mathrm{ZnO}$ QDs were shown in Figure 3. The bacterial growth rate (in comparison to the control, without QDs) was found to get slower with increasing concentrations of $\mathrm{ZnO}$ QDs. The growth rate constant and mean generation time in LB without $\mathrm{ZnO}$ QDs $(\mu=$ $0.019 \mathrm{~min}^{-1}, \mathrm{~g}=36.5 \mathrm{~min}$ ) was significantly affected on addition of ZnO QDs ( $\mu=0.013 \mathrm{~min}^{-1}$; g = $53.3 \mathrm{~min}$; at $400 \mathrm{mg} / \mathrm{L}$ ). Growth was completely arrested at $500 \mathrm{mg} /$ L QDs.

\section{Description of class 1 integron and phylogenetic position of $d f r A 30$}

The $\mathrm{Int}_{2} \mathrm{~F}$ and 3 " CS primer pair yielded $\sim 1.3 \mathrm{~kb}$ amplicon from the strain MB45, comprising a single gene cassette. The gene cassette contained a 471 bp long ORF with $93 \%$ identity at the amino acid level to the DfrA5 (Ac. No. AJ419169) of E. coli. The deduced DfrA30

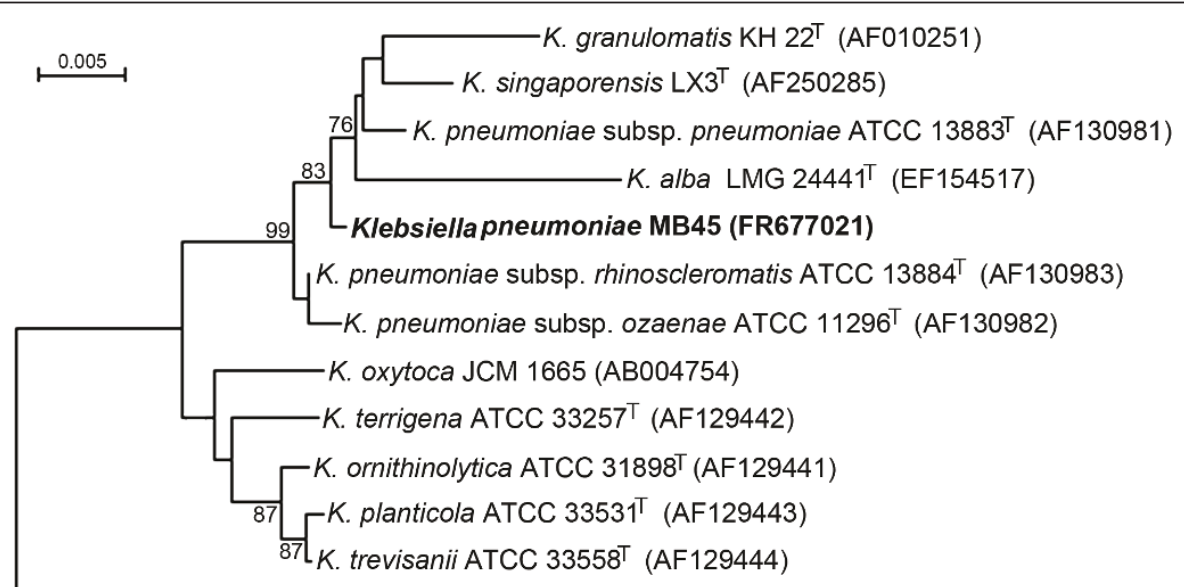

Budvicia aquatica DSM 5075' (AJ233407)

Figure $1 \mathrm{~N}-\mathrm{J}$ tree based on 16S rRNA gene sequences showing the position of strain MB45 (Bold face) within the members of genus Klebsiella. Budvicia aquatica DSM 5075 (AJ233407) used as an outgroup. Bootstrap values (>70\%), expressed as a percentage of 1000 replications, are given at branching points. EMBL/GenBank accession numbers are given in parentheses. Bar, 0.005 substitutions per nucleotide position. 


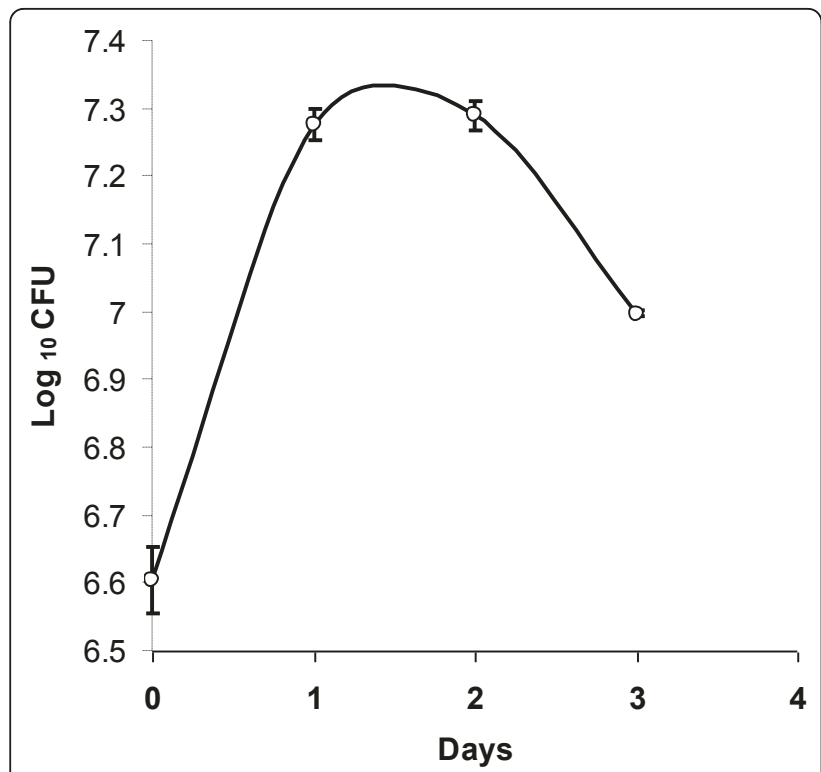

Figure 2 Viability and growth in diluted $\left(10^{-3}\right)$ Luria broth. Bars shows standard error.

protein sequence consists of 157 amino acids and thus was in the same size range as of DfrA5 (157 amino acids). Amino acid sequence comparison (identity) between the DfrA30 and the known TMP-resistant Dfr proteins ranges from 15.1-93\%. Maximum identity (93\% and $88.5 \%)$ of DfrA30 was with the Dfr proteins of $E$. coli (DfrA5, Ac. No. AJ419169 and DfrA14, Ac. No. AJ313522 respectively) and least (15.1\%) with the

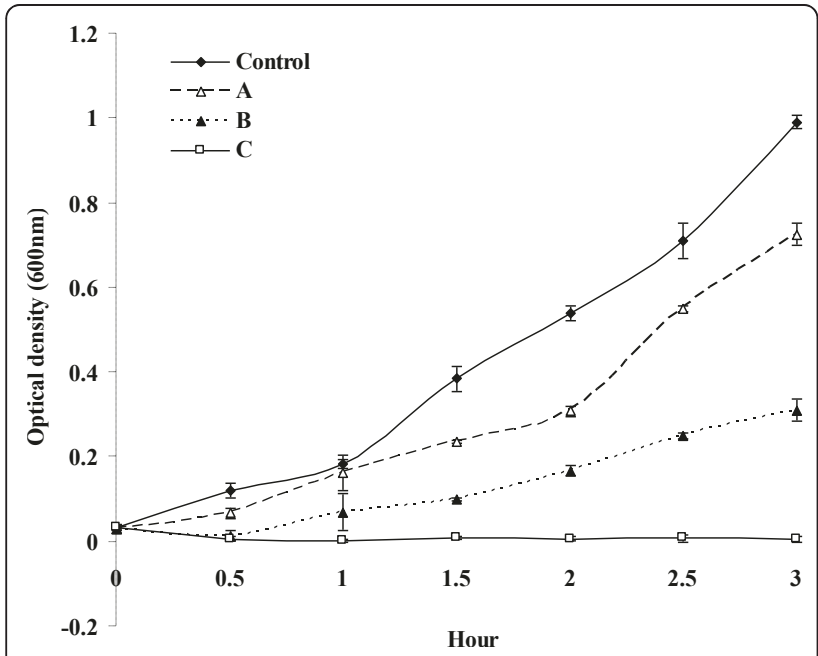

Figure 3 Effect of ZnO QDs on the growth of MB45. Cultures were setup with an initial cell number $9 \times 10^{6}$ cells in Luria broth amended with different concentration [solid rhombus $(\bullet)$, Control $0.0 \mathrm{mg} / \mathrm{L}$; open triangle $(\triangle)$, A $200 \mathrm{mg} / \mathrm{L}$; filled triangle $(\mathbf{\Delta}), \mathrm{B} 400$ $\mathrm{mg} / \mathrm{L}$; open rectangle ( $\square$ ), C $500 \mathrm{mg} / \mathrm{L}$ ] of colloidal solution of $\mathrm{ZnO}$ QDs. Cultures were incubated at $37^{\circ} \mathrm{C}$ with constant shaking at 200 rpm under normal laboratory condition. Bars shows standard error.
DfrA23 of S. typhimurium (Ac. No. AJ746361). The DfrA30 was 33.1\% identical to the chromosomal Dfr protein (encoded by folA) of E. coli K12 (Ac No. J01609). The 5" conserved sequence which terminates at the attI1 core site G/TTA, which marks the point of insertion and beginning of first gene cassette (EMBL nucleotide sequence position, 686; Ac. No. AM997279) was identical to those of class 1 integrons. The core site for the site-specific insertion, GTTAACC, was located at position 685-691. The ORF began with the initiation codon GTG at positions 705 to 707 and terminated with the stop codon TAA (within the inverse core site) at positions 1176 to 1178 . Downstream to the 3 " end of the $d f r A 30$ gene, an 81 bp long structure, recognized as an $a t t C$ site (59 base element) began with the sequence GGTTAAC (1L, inverse core site at position 1173-1179) and terminated with the core sequence GTTAGAT (EMBL nucleotide sequence position, 1253). Integrase binding domains 2L (TATGCAAT; position, 1185-1192) and 2R (ATTGATA; position, 1241-1247) within the 59 base element were also identified (Figure 4). Novel DfrA (DfrA30) from MB45 branched deeply with DfrA5 of $E$ coli in the NJ phylogenetic tree (Figure 5).

The clone, pAK45, conferred resistance to trimethoprim (MIC, $1000 \mathrm{mg} / \mathrm{L}$ ) and ampicillin (selection marker). The level of trimethoprim-resistance of the wild strain MB45 was noted $>1500 \mathrm{mg} / \mathrm{L}$. The MIC of the control strain (plasmidless JM109) was restricted to 5 $\mathrm{mg} / \mathrm{L}$ for trimethoprim.

Since the identity of translated $d f r A$ gene of MB45 was $93 \%$ with its nearest variant $d f r A 5$ gene (and this particular sequence deposited in the GenBank was annotated with the most similar features from the Feature database (FDB) as $d f r A 30$ [43]), this gene was predicted to be a new $d f r A$ gene and was named $d f r A 30$ following guidelines for naming new trimethoprim resistance genes $[15,44]$.

\section{Sequence alignment and Mutation study of DfrA30}

Multiple sequence alignment of DfrA30, DfrA5 and TMP-sensitive wild type (WT) Dfr protein (encoded by folA gene, Ac. No. J01609)] was done. Residues constituting the binding site for TMP [45], positions of the mutated amino acids in the active site of DfrA30 with respect to the wild type protein and also the non active site residues that are known to play a vital role in TMP binding were identified (Figure 6) [46]. The 3-dimensional structure of Dfr (PDB ID: 2W3V) depicting the active site pocket including the two important residues (positions 28 and 94) for TMP binding was analysed (Figure 7). The sequence alignment between wild type (WT) and Mycobacterium avium Dfr (PDB ID: 2W3V) (which was used to visualize the ligand binding) is available as Additional file 1: Figure S1. 


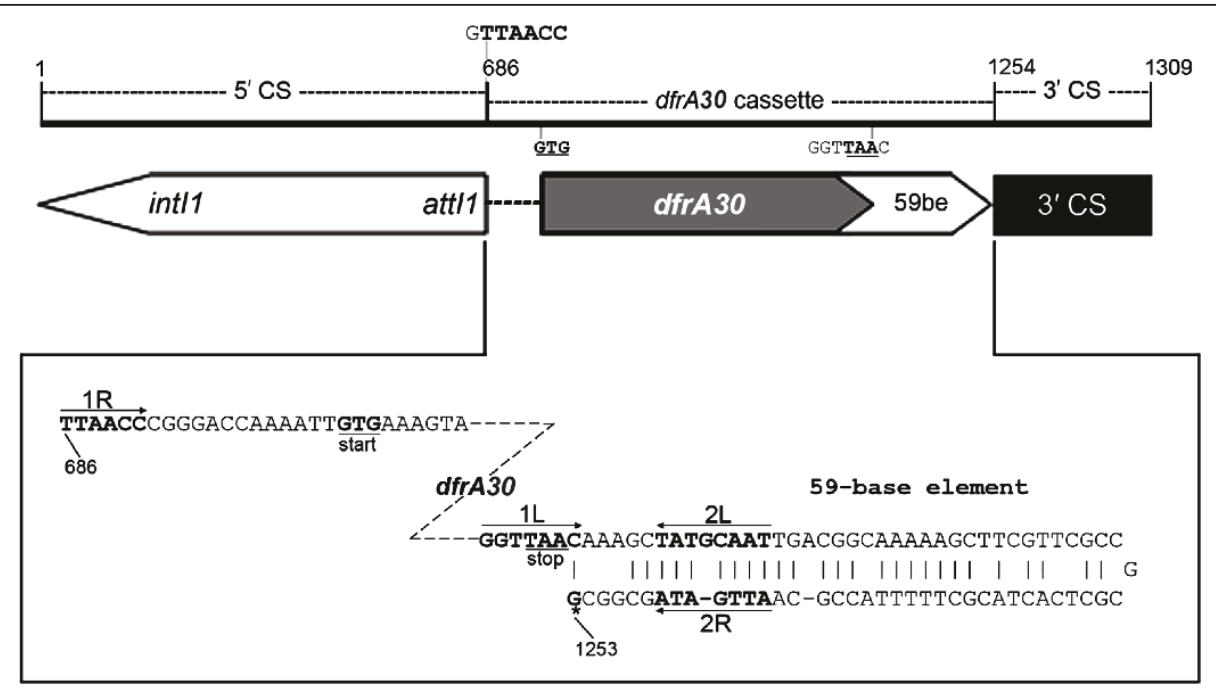

Figure 4 Schematic representation of the $\operatorname{Int}_{2} \mathrm{~F}-\mathbf{3}^{\prime} \mathrm{CS}$ amplicon of the strain MB45. CS, conserved segment; intl1, integrase gene; attl1, attachment site; $d f r$, dihydrofolate reductase; be, base element. Black thick bar shows the distribution of integron features on amplified product. The translation start (GTG) and stop (TAA) codon are in underlined bold face. In the 59 be, the putative integrase binding sites $1 \mathrm{~L}, 2 \mathrm{~L}$, $1 R$ and $2 R$ are indicated by arrows. Termination of 59 be is indicated by star (*). Numbers correspond to sequence positions in EMBL Ac. No. AM997279.

\section{Discussion}

Recent studies have shown that the frequency of antibiotic resistance has been the second highest in the genus Klebsiella especially in K. pneumoniae (next to E. coli) within the family Enterobacteriaceae; and the rate of occurrence has been noted to be higher in isolates from developing countries than the developed countries [12,47-49]. The incidence rates of trimethoprim resistance in Klebsiella spp. and E. coli in particular have been alarming [12,50-52] in the context of an earlier surveillance study (1987-88) on community isolates revealing an increase in trimethoprim resistance from $15.2 \%$ to $24 \%$ in Klebsiella/Enterobacter spp [17]. The most frequent mechanism of bacterial trimethoprimresistance is the production of an additional trimethoprim-resistant Dfr, regularly found on mobile genetic elements (plasmids, transposons, gene cassettes) [14,17]. Other mechanisms of bacterial resistance to trimethoprim that have been described are impermeability (found in isolates of Serratia, Enterobacter, Klebsiella, Pseudomonas, and Clostridium) and mutational changes in the thymidylate synthase gene $[14,17,53]$. Besides antibiotic resistance, incidence of serum resistance in clinical isolates of pathogenic bacteria is an additional threat. There appears to be a strong correlation between serum resistance and the ability of a variety of gramnegative bacteria to invade and survive in the human blood stream [54]. Earlier authors have developed a simple and rapid assay for determination of serum bactericidal activity using more than hundred clinical isolates of $K$. pneumoniae and have found that $50 \%$ were resistant to $20 \%$ normal human serum [33]. Nosocomial septicemia due to extended spectrum $\beta$-lactamase producing K. pneumoniae and E. coli are a therapeutic challenge due to resistance [9]. Recently, it was shown that treatment without resistance selection at the infection site with fluoroquinolone treatment can be linked to colonization of the digestive tract by $K$. pneumoniae (targeted pulmonary bacteria), followed by the emergence of resistance [8]. Complete sequence of $K$. pneumoniae multidrug resistance plasmid pKP048 has revealed the presence of several important resistance genes, such as bla (KPC-2), bla (DHA-1), qnrB4, and $\operatorname{arm} A$, which confer resistance to carbapenems, cephalosporins, fluoroquinolones, and aminoglycosides, respectively [10]. In the present study, the test strain, MB45, isolated from river Mahananda at Siliguri, India, is resistant to serum as well as to antibiotics trimethoprim, cotrimoxazole, ampicillin, gentamycin, netilmicin, tobramycin, chloramphenicol, cefotaxime, kanamycin and streptomycin and could survive in low nutrient condition (oligotrophic).

Characterization of integron-borne cassette arrays in K. pneumonia strains from China revealed a predominance of $d f r$ and aadA cassettes that confer resistance to trimethoprim and aminoglycosides respectively [55]. However, the distribution of $d f r$ genes in $K$. pneumoniae was not known until recently a study on trimethoprim resistance in 54 trimethoprim resistant $K$. pneumoniae isolates have revealed the presence of $d f r A 1, d f r A 5$, $d f r A 7, d f r A 8, d f r A 12, d f r A 14, d f r A 17$ and class 1 and 2 integrons; $d f r A 1$ and $d f r A 17$ being most prevalent and rarest respectively [48]. More than 25 different TMPresistance-mediating $d f r$ genes isolated from different 
bacteria, subdivided into two major types, 1 and 2 (referred as $d f r A$ and $d f r B$ ), have been observed till date $[56,57]$. A novel trimethoprim resistance gene is claimed when the translated Dfr encoded by the gene has $<95 \%$ identity at the amino acid level compared with known Dfr proteins [15]. Since the degrees of identity between the DfrA30 and the protein sequences of other Dfr(s) ranged between 15.1 and 93\%, thus placing DfrA5 and DfrA30 in an indisputable monophyletic group in the phylogenetic analysis (Figure 5).

The strain MB45 showed high level of resistance to TMP (>1500 mg/L). Generally, a single mutation in the active site is enough for TMP-resistance in Dfr, though multiple mutations are common in clinically isolated species. The mutations in the active site residues reduce the binding affinity of the enzyme for the drug. Matthews and co-workers have identified the residues that constitute the TMP-binding site in E. coli Dfr (Figure 6) [45]. Additionally, the mutations in the active site that lead to TMP resistance in E. coli have been enunciated [46]. The mutations in DfrA30 are of the same type as those in DfrA5. In particular, two changes, glutamine for leucine at residue 28 and isoleucine to serine at 94, would change the hydrophobic/polar nature at the two

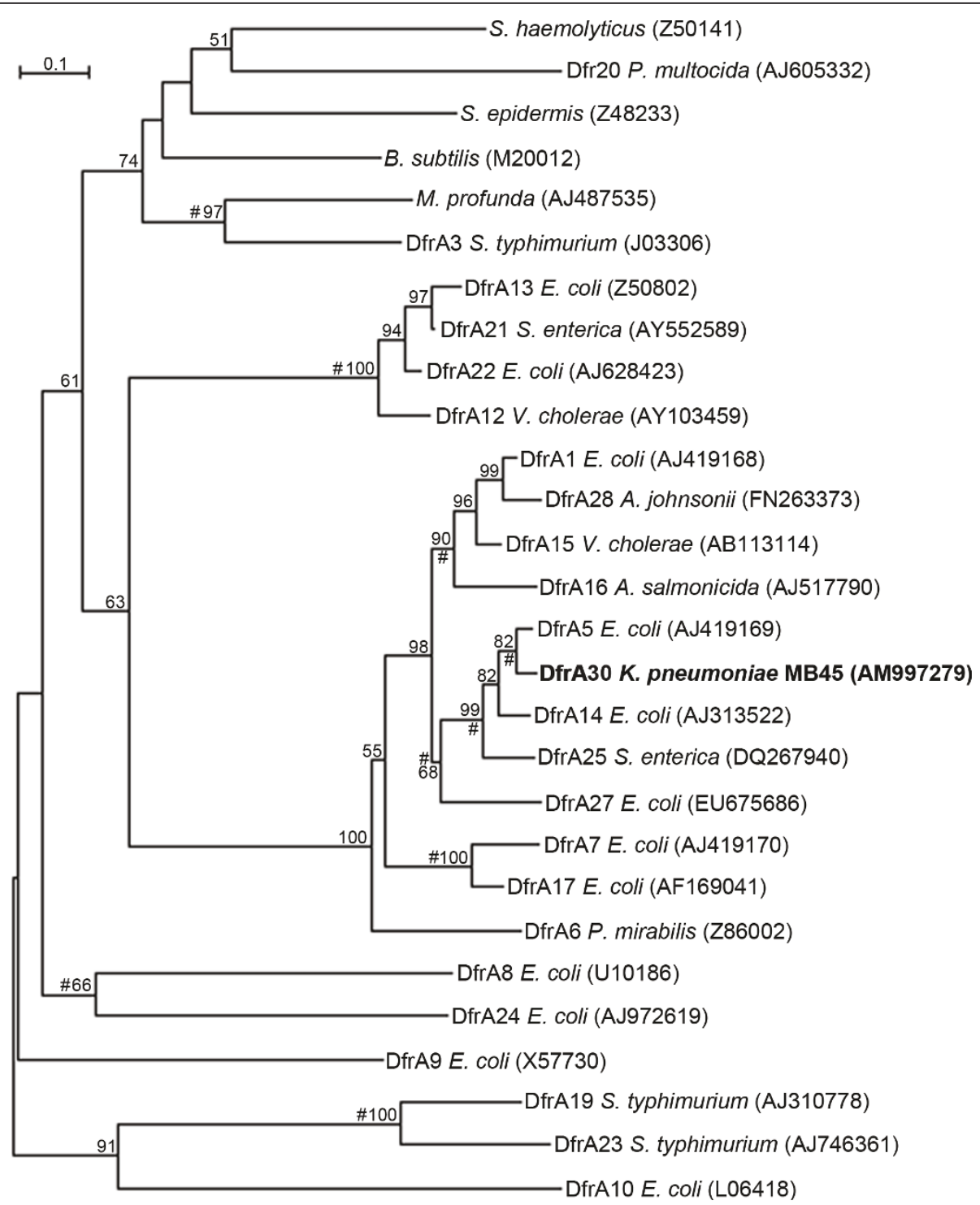

Figure 5 Phylogenetic tree showing the position of DfrA30 (Bold face) within the DfrA proteins involved in trimethoprim resistance. The number $(>50 \%)$ at each major branch point refers to the percentage of times that a particular node was found in 1,000 bootstrap replications. Source and the GenBank/EMBL/DDBJ accession (in parentheses) numbers are given for each DfrA protein. DfrB proteins, which differ distinctly from DfrA proteins in size and structure, are not included in this tree. Common clusters obtained from NJ, MP and UPGMA tree are represented by hash (\#). 


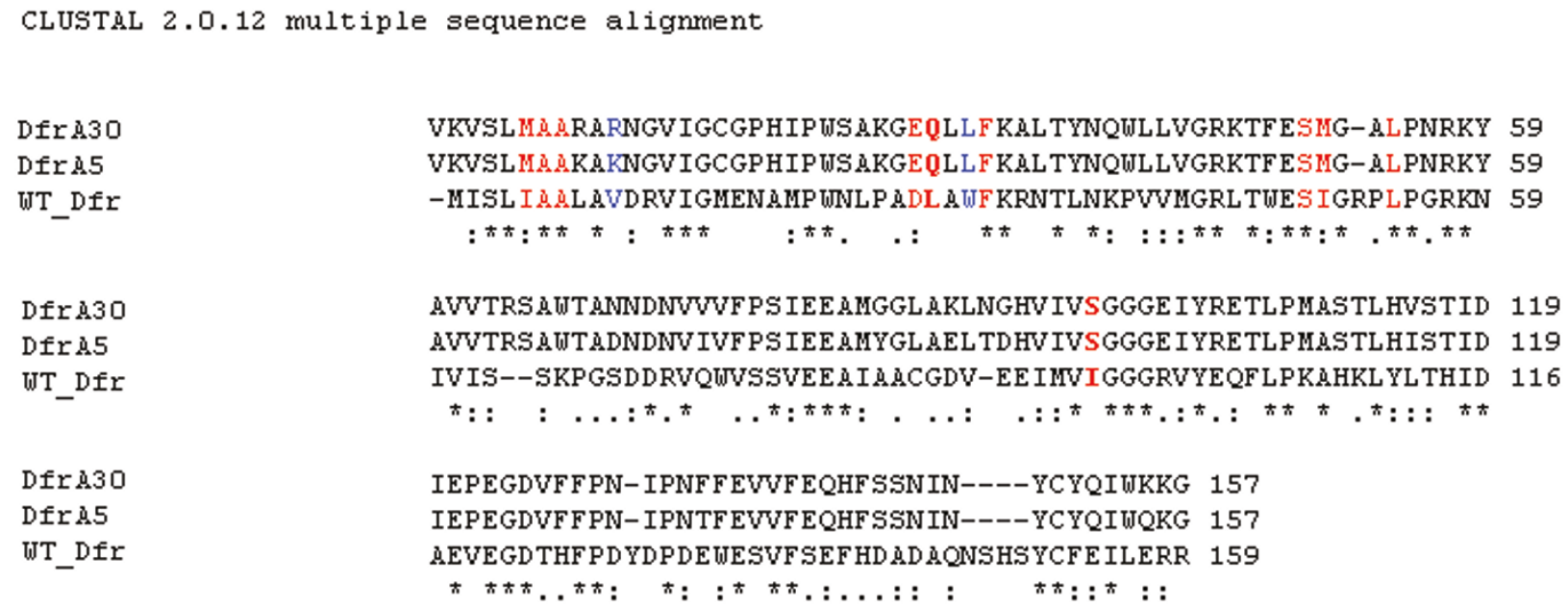

Figure 6 Sequence alignment of DfrA30 with DfrA5 and sensitive WT-Dfr protein. The residues which form the binding site [43] are shown in red, and the positions of mutations from the wild type (WT) protein are shown in red bold letters. Residues (beyond the active site) which are known to play an important role in trimethoprim binding [44], and which have been mutated are marked in blue.

opposite sides of the TMP site (Figure 7), thus possibly weakening the binding. Other mutations (V10, W30 and 194) beyond the active site have also been identified in clinically isolated TMP-resistant genes [46]. Some of these are also found in DfrA30 (mutations V10K and W31L) (Figure 6).

The percent occurrence of integron-positive isolates from clinical samples was much higher compared to environmental samples including fish farms [58-62], irrigation water sources [63] and other aquatic environments [23,26,64-66]. Except one recent study [23], in all

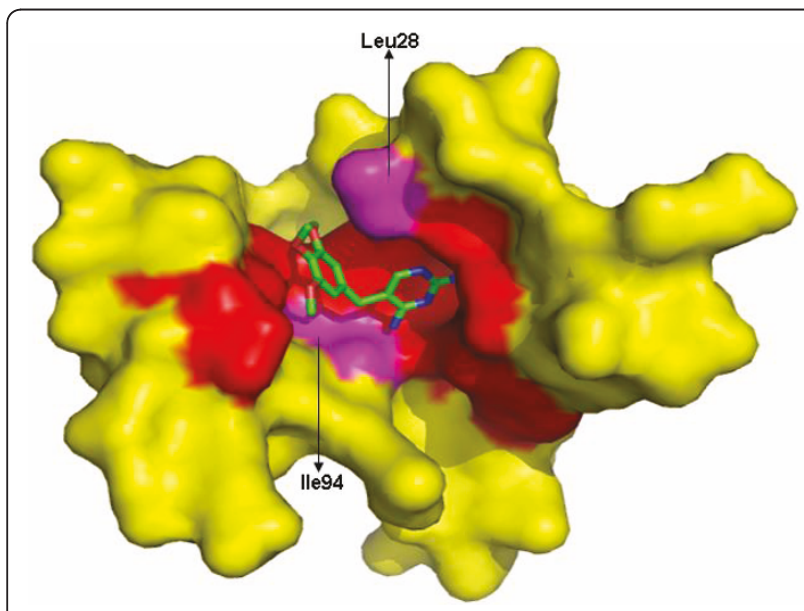

Figure 7 Surface representation of TMP binding site on DFR (PDB ID: 2W3V). Residues which form the active pocket are shown in red, and the two residues that are mutated in DfrA30 are in magenta; the remaining residues are in yellow. TMP is shown in stick model. other studies the incidence of class 1 integrons was observed for copiotrophic isolates that grow on rich nutrient medium. The test strain, MB45, is a multipleantibiotic resistant oligotrophic bacteria recovered on 0.001X LA from river Mahananda. The facultatively oligotrophic strain used in this study was characterized as K. pneumoniae MB45 (ascertained from phenotype as well as from 16S rRNA phylogeny) (Figure 1). Viability assay and growth assessment of $K$. pneumoniae MB45 cell concentrate in $0.001 \mathrm{X}$ Luria broth for more than 72 $h$ by taking viable cell count of the cell suspension on 1X LA at different times (Figure 2) demonstrated its ability to adapt both oligotrophic (ability to survive and grow in extremely poor nutrient conditions) as well as copiotrophic (ability to form colonies in a rich medium) conditions of growth. Such facultative nature of oligotrophy, as shown by the K. pneumoniae MB45, may contribute to the reported adaptation of remaining viable in hospital environment [28] for several days and cause nosocomial infection. Microbial contamination of working surfaces, clinical materials, and surgical devices poses a major threat in hospitals and intensive care units. With increasing threat because of greater incidence of multiple antibiotic resistant pathogens there is increased demand for novel disinfectants and disinfection methods. Due to exceptional physical and chemical properties of nanostructured materials there have been several attempts to improve the bactericidal activity of metal nanoparticles $[31,67,68]$. Most of these studies were confined to testing the nanoparticles on therapeutically sensitive test strains of E. coli (gram negative representative), Bacillus subtilis and Staphylococcus 
aureus (gram positive representatives). In an earlier study investigating the role of surface bound anionic species on zinc oxide quantum dots for the antibacterial activity against $E$. coli, it was shown that ZnO QDs having acetate ions had superior bactericidal activity than those described earlier [31]. In this study, the antibacterial potency of $\mathrm{ZnO}$ QDs was tested against the multiple antibiotic and serum resistant $K$. pneumoniae MB45. The bacterial growth rate was found to be inhibited with the increase in concentration of $\mathrm{ZnO}$ QDs under standard cultural conditions (Figure 3). Complete inhibition of growth of MB45 is observed at concentration of $500 \mathrm{mg} / \mathrm{L} \mathrm{ZnO}$ QDs in the medium. Hence, in future $\mathrm{ZnO}$ QDs could be a good nanobiotic candidate for the control of multi-drug resistant pathogens as well as in disinfecting hospital environments, external wounds, medical and surgical devices; and also in suitable format may find application in drinking water treatment plants.

\section{Conclusion}

The present work showed a new dihydrofolate reductase gene, $d f r A 30$ responsible for high level of trimethoprimresistance $(>1500 \mathrm{mg} / \mathrm{L}$ and $1000 \mathrm{mg} / \mathrm{L}$ in K. pneumoniae MB45 and E. coli JM109 expressing dfrA30 gene cassette in pAK45 respectively). The strain MB45, isolated from river Mahananda was also resistant to nine more antibiotics as well as human serum; and was able to grow in very low nutrient condition for more than two days. Here we have suggested one of the possible ways to eradicate these pathogens by use of Zinc quantum dots (a nano-biotic) however other improved nanobiotics (experiments with $\mathrm{ZnO}$-QDs having other capping agents are in progress) can also be used.

\section{Additional material}

Additional file 1: Figure S1 - Sequence alignment between wild type (WT) and Mycobacterium avium Dfr (PDB ID: 2W3V).

\section{Acknowledgements}

We are thankful to our colleagues S.P. Singh, S. Mukherjee, S. Bhowal, K. K. Yadav, P. Singh, A.K. Mandal, B. K. Tiwary, G. D. Purkayastha, A. Ghosh, K. K. Singh and Papai Singha (Lab attendant) for their active support.

Funding: The consumables for research work were supported from a research grant (grant number, BT/PR-164/BCE/08/448/2006) from Department of Biotechnology (DBT), Government of India. One of the authors, Arvind Kumar, was provided with independent Ph.D studentship (Award No. DBT-JRF/05-06/71/29.08.05)

\section{Author details}

${ }^{1}$ Omics Laboratory, Department of Biotechnology, University of North Bengal, Raja Rammohunpur, P.O. NBU, Siliguri 734 013, West Bengal, India. ${ }^{2}$ Department of Biochemistry, Bose Institute, Kolkata 700 054, India. ${ }^{3}$ National Physical Laboratory, New Delhi 110 012, India.

\section{Authors' contributions}

All experimental work, data collection and analysis, phylogenetic analysis, literature search and writing of the draft manuscript were done by AK under the guidance of RC. ZnO- quantum dots were provided by SC and synthesis of $\mathrm{ZnO}$ - quantum dots was done by PJ. SC and PK were responsible for insilco mutational study of novel gene, dfrA30. RC was responsible for study concept, designing and coordinating the research, supervising the work and finalizing the manuscript. All authors have read, suggested changes/editing, and approved the final manuscript.

\section{Competing interests}

The authors declare that they have no competing interests.

Received: 14 December 2010 Accepted: 19 May 2011

Published: 19 May 2011

\section{References}

1. Bagley ST: Habitat association of Klebsiella species. Infect Control 1985, 6:52-58.

2. Podschun R, Pietsch S, Höller C, Ullmann U: Incidence of Klebsiella Species in Surface Waters and Their Expression of Virulence Factors. Appl Environ Microbiol 2001, 67:3325-3327.

3. Banu N, Menakuru H: Enumeration of microbial contaminants in sachet water: a public health challenge. Health 2010, 2:582-588.

4. Li X, Zhang D, Chen F, Ma J, Dong Y, Zhang L: Klebsiella singaporensis sp. nov., a novel isomaltulose-producing bacterium. Int J Syst Evol Microbiol 2004, 54:2131-2136.

5. Xu J, Li W, Chen X, Zhou Y: Klebsiella alba sp. nov., a novel pesticidetolerant bacterium from a heavily polluted environment. J Gen Appl Microbiol 2010, 56:241-247.

6. Ryan KJ, Ray CG: Sherris Medical Microbiology. McGraw Hill, 4 2004, 370.

7. Nordmann P, Cuzon G, Naas T: The real threat of Klebsiella pneumoniae carbapenemase-producing bacteria. Lancet Infect Dis 2009, 9:228-236.

8. Kesteman AS, Guyomard AP, Laurentie M, Sanders P, Toutain PL, BousquetMélou A: Emergence of Resitant Klebsiella pneumoniae in the Intestinal Tract during Successful Treatment of Klebsiella pneumoniae Lung Infection in Rats. Antimicrob Agents Chemother 2010, 54:2960-2964.

9. Taneja J, Mishra B, Thakur A, Dogra V, Loomba P: Nosocomial bloodstream infections from extended-spectrum-beta-lactamase-producing Escherichia coli and Klebsiella pneumoniae from GB Pant Hospital, New Delhi. J Infect Dev Ctries 2010, 4:517-520.

10. Jiang Y, Yu D, Wei Z, Shen P, Zhou Z, Yu Y: Complete nucleotide sequence of Klebsiella pneumoniae multidrug resistance plasmid pKP048, carrying bla $a_{\mathrm{KPC}-2}, b / a_{\mathrm{DHA}-1}, q n r B 4$, and armA. Antimicrob Agents Chemother 2010, 54:3967-3969.

11. Casewell MW, Talsania HG: Multiple antibiotic resistance and capsular types of gentamicin-resistant Klebsiella aerogenes. J Antimicrob Chemother 1981, 7:237-244

12. Adrian PV, Koornhof HJ, Wylie BA: Trimehtoprim Resistance in South African Isolates of Aerobic Gram-Negative Faecal Flora. Eur J Clin Microbiol Infect Dis 1993, 12:916-921.

13. Vranic-Ladavac M, Bosnjak Z, Beader N, Barisic N, Kalenic S, Bedenic B: Clonal spread of CTX-M-15-producing Klebsiella pneumoniae in a Croatian hospital. J Med Microbiol 2010, 59:1069-1078.

14. Huovinen P, Sundstrom L, Swedberg G, Sköld O: Trimethoprim and sulfonamide resistance. Antimicrob Agents Chemother 1995, 39:279-289.

15. Agersø $Y$, Peirano G, Aarestrup FM: dfrA25, a novel trimethoprim resistance gene from Salmonella agona isolated from a human urine sample in Brazil. J Antimicrob Chemother 2006, 58:1044-1047.

16. Gillings MR, Holley MP, Stokes HW, Holmes AJ: Integrons in Xanthomonas: a source of species genome diversity. Proc Natl Acad Sci USA 2005, 102:4419-4424.

17. Amyes SGB, Towner KJ: Trimethoprim resistance, epidemiology and molecular aspects. J Med Microbiol 1990, 31:1-19.

18. Parsons Y, Hall RM, Stokes HW: A New Trimethoprim Resistance Gene, dhfrX, in the In7 Integron of Plasmid pDGO100. Antimicrob Agents Chemother 1991, 35:2436-2439.

19. Young HK, Amyes SG: A New Mechanism of Plasmid Trimethoprim Resistance. J Biol Chem 1986, 261:2503-2505.

20. Towner KJ, Venning BM, Pinn PA: Occurrence of transposable trimethoprim resistance in clinical isolates of Escherichia coli devoid of self-transmissible resistance plasmids. Antimicrob Agents Chemother 1982, 21:336-338. 
21. Grape M, Sundström L, Kronvall G: Two new dfr genes in trimethoprimresistant integron-negative Escherichia coli isolates. Antimicrob Agents Chemother 2007, 51:1863-1864.

22. Wei $Q$, Jiang $X$, Yang $Z$, Chen N, Chen $X, L i ~ G, L u$ Y: dfrA27, a new integron-associated trimethoprim resistance gene from Escherichia coli. J Antimicrob Chemother 2009, 63:405-419.

23. Kumar A, Mukherjee $S$, Chakraborty R: Characterization of a Novel Trimethoprim Resistance Gene, dfrA28, in Class 1 Integron of an Oligotrophic Acinetobacter johnsonii Strain, MB52, Isolated from River Mahananda, India. Microb Drug Resist 2010, 16:29-37.

24. Hall RM, Collis CM: Mobile gene cassettes and integrons: capture and spread of genes by site-specific recombination. Mol Microbiol 1995, 15:593-600.

25. Leverstein-van Hall MA, M Blok HE, T Donders AR, Paauw A, Fluit AC, Verhoef J: Multidrug resistance among Enterobacteriaceae is strongly associated with the presence of integrons and is independent of species or isolate origin. J Infect Dis 2003, 187:251-259.

26. Mukherjee $S$, Chakraborty R: Incidence of class 1 integrons in multiple antibiotic-resistant Gram-negative copiotrophic bacteria from the River Torsa in India. Res Microbiol 2006, 157:220-226.

27. Hendricks CW: Enteric Bacterial Growth Rates in River Water. Appl Microbiol 1972, 24:168-174.

28. Tada Y, Ihmori M, Yamaguchi J: Oligotrophic Bacteria Isolated from Clinical Materials. J Clin Microbiol 1995, 33:493-494.

29. Reasoner DJ, Gerldreich EE: A new medium for the enumeration and subculture of bacteria from potable water. Appl Environ Microbiol 1985, 49:1-7.

30. Oh H, Lee J, Kim K, Kim J, Choung Y, Park J: A novel laboratory cultivation method to examine antibiotic-resistance-related microbial risks in urban water environments. Water Sci Technol 2009, 59:346-352.

31. Joshi P, Chakraborti S, Chakrabarti P, Haranath D, Shanker V, Ansari ZA, et al: Role of Surface Adsorbed Anionic Species in Antibacterial Activity of ZnO Quantum Dots Against Escherichia coli. J Nanosci Nanotechnol 2009, 9:6427-6433.

32. Roberta B, Roselyne F, Nicolas B, Shakib B, Marc FB, Fernand F: Toxicological impact studies based on Escherichia coli bacteria in ultrafine ZnO nanaoparticles colloidal medium. Nano Lett 2006, 6:866-870.

33. Sharma KS, Fatma T, Thukral SS: A simple rapid serum bactericidal assay and its evaluation in clinical isolates of Klebsiella pneumoniae. J Microbiol Methods 1999, 39:45-48.

34. Tamura K, Dudley J, Nei M, Kumar S: MEGA4: Molecular Evolutionary Genetics Analysis (MEGA) software version 4.0. Mol Biol Evol 2007, 24:1596-1599.

35. Thompson JD, Higgins DG, Gibson TJ: CLUSTALW: improving the sensitivity of progressive multiple sequence alignment through sequence weighting, position-specific gap penalties and weight matrix choice. Nucleic Acid Res 1994, 22:4673-4680.

36. Saitou N, Nei M: The neighbor-joining method: A new method for reconstructing phylogenetic trees. Mol Biol Evol 1987, 4:406-425.

37. Eck RV, Dayhoff MO: Atlas of Protein Sequence and Structure National Biomedical Research Foundation, Springs Silver, Maryland; 1966.

38. Felsenstein J: Confidence limits on phylogenies: An approach using the bootstrap. Evolution 1985, 39:783-791.

39. Lévesque $C$, Piché $L$, Larose $C$, Roy PH: PCR mapping of integrons reveals several novel combinations of resistance genes. Antimicrob Agents Chemother 1995, 39:185-191.

40. Martinez-Freijo P, Fluit AC, Schmitz FJ, Grek VS, Verhoef J, Jones ME: Class I integrons in Gram-negative isolates from different European hospitals and association with decreased susceptibility to multiple antibiotic compounds. J Antimicrob Chemother 1998, 42:689-696.

41. Sneath PHA, Sokal RR: Numerical Taxonomy Freeman, San Francisco; 1973.

42. Berman HM, Westbrook J, Feng Z, Gilliland G, Bhat TN, Weissig H, Shindylov IN, Bourne PE: The Protein Data Bank. Nucleic Acids Res 2000, 28:235-242.

43. Partridge SR, Tsafnat G, Coiera E, Iredell J: Gene cassettes and cassette arrays in mobile resistance integrons. FEMS Microbiol Rev 2009, 33:757-784.

44. Hall R, Partridge S: Unambiguous numbering of antibiotic resistance genes. Antimicrob Agents Chemother 2003, 47:3998

45. Matthews DA, Bolin JT, Burridge JM, Filman DJ, Volz KW, Kaufman BT, Beddell CR, Champness JN, Stammers DK, Kraut J: Refined Crystal
Structures of Escherichia coli and Chicken Liver Dihydrofolate Reductase Containing Bound Trimethoprim. J Biol Chem 1985, 260:381-391.

46. Watson M, Liu WJ, Ollis D: Directed evolution of trimethoprim resistance in Escherichia coli. FEBS J 2007, 274:2661-2671.

47. Randrianirina F, Vaillant $L$, Ramarokoto CE, Rakotoarijaona A, Andriamanarivo ML, Razafimahandry HC, Randrianomenjanahary J, Raveloson JR, Hariniana ER, Carod JF, Talarmin A, Richard V: Antimicrobial resistance in pathogens causing nosocomial infections in surgery and intensive care wards in Antananarivo, Madagascar. J Infect Dev Ctries 2010, 4:74-82.

48. Brolund A, Sundqvist M, Kahlmeter G, Grape M: Molecular Characterisation of Trimethoprim Resistance in Escherichia coli and Klebsiella pneumoniae during a Two Year Intervention on Trimethoprim Use. PLOS ONE 2010, 5:e9233.

49. Lopes ACS, Veras DL, Lima AM, Melo Rde CA, Ayala J: blaCTX-M-2 and blaCTX-M-28 extended-spectrum $\beta$-lactamase genes and class 1 integrons in clinical isolates of Klebsiella pneumoniae from Brazil. Mem Inst Oswaldo Cruz 2010, 105:163-167.

50. Misra R, Kumar M, Menon PK, Ohri VC: Plasmid mediated antibiotic resistance in Klebsiella pneumoniae. Indian J Pathol Microbiol 2001, 44:427-429.

51. Motakefi A, Sundqvist M, Kahlmeter G, Grape M: Differences in the distribution of common trimethoprim resistance $d f r$-genes in $E$. coli and K. pneumoniae. Abstract of the 18th European Congress of Clinical Microbiology and Infectious Diseases Barcelona, Spain, 2008. Abstract P-2023, Europian Society of Microbiology and Infectious Diseases, Basel, Switzerland.

52. Penteado AP, Castanheira M, Pignatari ACC, Guimarães T, Mamizuka EM, Gales AC: Dissemination of bla $a_{\mathrm{IMP}-1}$-carrying integron In86 among Klebsiella pneumoniae isolates harboring a new trimethoprim resistance gene dfr23. Diagn Microbiol Infect Dis 2009, 63:87-91.

53. Then RL: Mechanisms of resistance to trimethoprim, the sulfonamides, and trimethoprim-sulfamethoxazole. Rev Infect Dis 1982, 4:261-269.

54. Taylor PW: Bacterial resistance to complement. In Virulence Mechanisms of Bacterial Pathogenesis. Edited by: Roth JA. American Society of Microbiology, Washington, DC; 1988:107-120.

55. Yao F, Qian $Y$, Chen S, Wang P, Huang $Y$ : Incidence of extended spectrum $\beta$-lactamases and characterization of integrons in extended spectrum $\beta$ lactamase-producing Klebsiella pneumoniae isolated in Shantou, China. Acta Biochim Biophys Sin (Shanghai) 2007, 39:527-532

56. Pattishall KH, Acar J, Burchall JJ, Goldstein FW, Harvey RJ: Two distinct types of trimethoprim-resistant dihydrofolate reductase specified by Rplasmids of different compatibility groups. J Biol Chem 1977, 252:2319-2323

57. White PA, Rawlinson WD: Current status of the aadA and dfr gene cassette families. J Antimicrob Chemother 2001, 47:495-496.

58. Petersen A, Guardabassi L, Dalsgaard A, Olsen JE: Class I integrons containing a $d h f r l$ trimethoprim resistance gene cassette in aquatic Acinetobacter spp. FEMS Microbiol Lett 2000, 182:73-76.

59. Schmidt AS, Bruun MS, Larsen JL, Dalsgaard I: Characterization of class 1 integrons associated with R-plasmids in clinical Aeromonas salmonicida isolates from various geographical areas. J Antimicrob Chemother 2001, 47:735-743.

60. Agers $\varnothing$ Y, Petersen A: The tetracycline resistance determinant Tet 39 and the sulphonamide resistance gene sulll are common among resistant Acinetobacter spp. isolated from integrated fish farms in Thailand. J Antimicrob Chemother 2007, 59:23-27.

61. Čižek A, Dolejská M, Sochorová R, Strachotová K, Piačková V, Veselý T: Antimicrobial resistance and its genetic determinants in aeromonads isolated in ornamental (koi) carp (Cyprinus carpio koi) and common carp (Cyprinus carpio). Vet Microbiol 2010, 142:435-439.

62. Ozgumus OB, Sandalli C, Sevim A, Celik-Sevim E, Sivri N: Class 1 and class 2 integrons and plasmid-mediated antibiotic resistance in coliforms isolated from ten rivers in Northern Turkey. J Microbiol 2009, 47:19-27.

63. Roe MT, Vega E, Pillai SD: Antimicrobial resistance markers of class 1 and class 2 integron-bearing Escherichia coli from irrigation water and sediments. Emerg Infect Dis 2003, 9:822-826.

64. Rosser SJ, Young HK: Identification and characterization of class 1 integrons in bacteria from an aquatic environment. J Antimicrob Chemother 1999, 44:11-18.

65. Gaze WH, Abdouslam N, Hawkey PM, Wellington EMH: Incidence of Class 1 Integrons in a Quaternary Ammonium Compound-Polluted Environment. Antimicrob Agents Chemother 2005, 49:1802-1807. 
66. Gillings M, Boucher Y, Labbate M, Holmes A, Krishnan S, Holley M, Stokes HW: The evolution of class 1 integrons and the rise of antibiotic resistance. J Bacteriol 2008, 190:5095-5100.

67. Ruparelia JP, Chatterjee AK, Duttagupta SP, Mukherji S: Strain specificity in antimicrobial activity of silver and copper nanoparticles. Acta Biomater 2008, 4:707-716.

68. Jones N, Ray B, Ranjit KT, Manna AC: Antibacterial activity of ZnO nanoparticle suspensions on a broad spectrum of microorganisms. FEMS Microbiol Lett 2008, 279:71-76.

69. Champs CD, Vellin JF, Diancourt L, Brisse S, Kemeny JL, Gilain L: Laryngeal Scleroma Associated with Klebsiella pneumoniae subsp. ozaenae. J Clin Microbiol 2005, 43:5811-5813.

70. Hansen DS, Aucken HM, Abiola T, Podschun R: Recommended Test Panel for Differentiation of Klebsiella Species on the Basis of a Trilateral Interlaboratory Evaluation of 18 Biochemical Tests. J Clin Microbiol 2004, 42:3665-3669.

doi:10.1186/1476-0711-10-19

Cite this article as: Kumar et al: A multiple antibiotic and serum resistant oligotrophic strain, Klebsiella pneumoniae MB45 having novel dfrA30, is sensitive to ZnO QDs. Annals of Clinical Microbiology and Antimicrobials 2011 10:19.

\section{Submit your next manuscript to BioMed Central} and take full advantage of:

- Convenient online submission

- Thorough peer review

- No space constraints or color figure charges

- Immediate publication on acceptance

- Inclusion in PubMed, CAS, Scopus and Google Scholar

- Research which is freely available for redistribution

Submit your manuscript at www.biomedcentral.com/submit
() Biomed Central 